\title{
Correction to: Discrete variable topology optimization for compliant mechanism design via Sequential Approximate Integer Programming with Trust Region (SAIP-TR)
}

\author{
Yuan Liang ${ }^{1} \cdot$ Kai Sun $^{1} \cdot$ GengDong Cheng ${ }^{1}$ (])
}

Published online: 22 October 2021

๑) Springer-Verlag GmbH Germany, part of Springer Nature 2021

\section{Correction to: \\ Structural and Multidisciplinary Optimization (2020) 62:2851-2879 \\ https://doi.org/10.1007/s00158-020-02693-2}

In the original publication of the article, first author's name was misspelt. The correct name is given in this correction.

Publisher's Note Springer Nature remains neutral with regard to jurisdictional claims in published maps and institutional affiliations.

The original article can be found online at https://doi.org/10.1007/ s00158-020-02693-2.

\section{GengDong Cheng}

chenggd@dlut.edu.cn

1 State Key Laboratory of Structural Analysis for IndustrialEquipment, Department of Engineering Mechanics, DalianUniversity of Technology, Dalian 116023, People's Republic of China 